\title{
Theoretical Study on the Structural Effect of Benzoxazin Derivative as Corrosion Inhibitor for Carbon Steel in Acid Media
}

\author{
MAGDALENE EDET IKPI* and FIDELIS EBUNTA ABENG \\ Corrosion and Electrochemistry Research Laboratory, Department of Pure and Applied \\ Chemistry, University of Calabar, P.M.B. 1115, Calabar-Nigeria \\ meikpi@unical.edu.ng
}

Received 8 July 2017 / Accepted 20 July 2017

\begin{abstract}
Drug-based compounds are eco-friendly, nontoxic, inexpensive and easily accessible source of material which can consecutively be used as corrosion inhibitor for carbon steel in acid media. The effect of benzoxaxin derivative, a drug-based compound was investigated by theoretical advance study. The energy of the highest occupied molecular orbital (EHOMO), energy of the lowest unoccupied molecular orbital (ELUMO), the energy gap $(\Delta \mathrm{E})$, dipole moment $(\mu)$ mullikencharge of heteroatoms, ionization potential (IP), electron affinity (EA), electronegativity $(\chi)$, global hardness $(\eta)$ and global softness $(\sigma)$ were calculated and interpreted. Quantum chemical calculations revealed the adsorption of the molecules on the metal surface.
\end{abstract}

Keywords: DFT, Corrosion inhibition, Adsorption mechanism, Benzoxazin

\section{Introduction}

Levofloxacin is an antibiotic drug, derived from benzoxazin compound. Benzoxazin compound constitutes organic material and mostly having heterocyclic atoms such as $\mathrm{N}, \mathrm{O}$ and $\mathrm{S}$ either in the aromatic or long carbon chain. Such systemic arrangement has been reported as effective inhibitors ${ }^{1}$. These inhibitors have extended $\pi$-electron systems and functional groups, such as $-\mathrm{C}=\mathrm{C}-,-\mathrm{OH}$ and $-\mathrm{NH}_{2}$. The functional groups provide electrons that facilitate adsorption of the inhibitors on the metal surface ${ }^{2}$. Some drug-based compounds have been reported as good corrosion inhibitors in acidic media ${ }^{3-12}$. Corrosion inhibitors promote film formation on the metal surface through transfer of electrons from the organic compounds to the metal, forming a donor-acceptor bond during adsorption process ${ }^{1}$. In such adsorption, the metal functions as an electrophile while the inhibitor acts as a nucleophile $^{13}$. Experimental investigation of the action of levofloxacin drug, a derivative of benzoxazin compound on the corrosion inhibition of carbon steel in $2 \mathrm{M} \mathrm{HCl}$ solution has been reported ${ }^{14}$. The experimental means were useful in explaining the inhibition mechanism but they are often expensive and time consuming. Advances in computer hardware and in theoretical chemistry have brought high performance computing and graphical 
tools within the reach of many academic and industrial laboratory ${ }^{15}$. Currently, corrosion publications containing quantum chemical calculations are used to explore the electronic properties of inhibitors. The energy of the frontier molecular orbitals $\left(\mathrm{E}_{\mathrm{HOMO}}\right.$ and $\left.\mathrm{E}_{\mathrm{LUMO}}\right)$, energy gap $(\Delta E)$, charge on the reactive center $\left(\mathrm{f}^{+}\right.$and $\left.\mathrm{f}\right)$, dipole moment $(\mu)$, global hardness $(\eta)$ and global softness $(\sigma)$ etc., have been investigated to achieve the appropriate correlation.

\section{Method of calculation}

There are various quantum-based advances that have been functional to organic materials design including; Hatree-fock, Moller-plesset, coupled cluster and semi empirical methods. Though the most fashionable organic material design and calculation of chemical reactivity has been density functional theory (DFT), the main reason for its popularity has been the relative accuracy with significantly lower computational cost compared to some of the other methods listed above. DFT centers on the electron density $P(r)$ itself as the carrier of all information in the molecular or atomic ground state rather than on the single electron wave function ${ }^{16}$. Since the electron density arises from the collective contribution of all electrons, the ground state total energy for an $N$-electron system is based on DFT given in terms of threedimensional ground-state electronic density $P(r)$ and the external potential $V(r)$ in the form ${ }^{16,17}$;

$$
E(p)=F(p)+\int P(r) V(r) d r
$$

Where $E(p)$ is the kinetic energy functional, $F(p)$ is universal functional of Hohenbergekohn given by the sum of the electronic kinetic energy functional while equation 2 guarantees the proper normalization of the electron density.

$$
N=\int P(r) d r
$$

A general form of the DFT expression is shown in equation 3 according to literature ${ }^{16-18}$,

$$
E_{D F T}(p)=T_{s}(p)+E_{n e}(p)+J(p)+E_{x c}(p)
$$

Where $T_{\mathrm{s}}$ refers to the kinetic energy functional (s indicates that the kinetic energy is obtained from a slater determinant), $E_{n e}$ the electron nuclear attraction functional, $J$ the coulomb part of the electron-electron repulsion functional and $E_{x c}$ the exchange correlation functional. Each of these terms depend on the electron density $p$ and is indicated by the symbol $p$ in brackets following each term. Since the exchange correlation energy functional is unknown, approximate solutions are obtained using the Kohn-Sham (KS) orbitals. These differ from other kinds of orbitals primarily on the basis that the sum of the squares of the occupied KS orbitals is the true electron density of the system ${ }^{16}$. The solution of the Euler-Langrange equation which corresponds to the minimization of the energy given in equation 1 together with the consideration of equation 2 allows for the ground-state electronic density to be calculated as;

$$
\mu=\left[\frac{\delta E}{\delta P(r) v}\right]=V(r)+\frac{\delta F}{\delta P(r)}
$$

Where $\mu$ is the undetermined Langrange multiplier representing the chemical potential that measures the escaping tendency of the electrons from a system ${ }^{16}$. DFT was performed with the aid of Gaussian 03 software suite to provide a complete geometry optimization.

\section{Results and Discussion}

The chemical structure of the compound under study is shown in Figure 1. The optimized molecular structure of the investigated compound using Backe's three parameter hybrid functional and Lee-Yang-Paar correlation functional (B3LYP) is shown in Figure 2. 
<smiles>C[C@H]1COc2c(N3CCN(C)CC3)c(F)cc3c(=O)c(C(=O)O)cn1c23</smiles>

Figure 1. Chemical structure of benzoxazin derivative

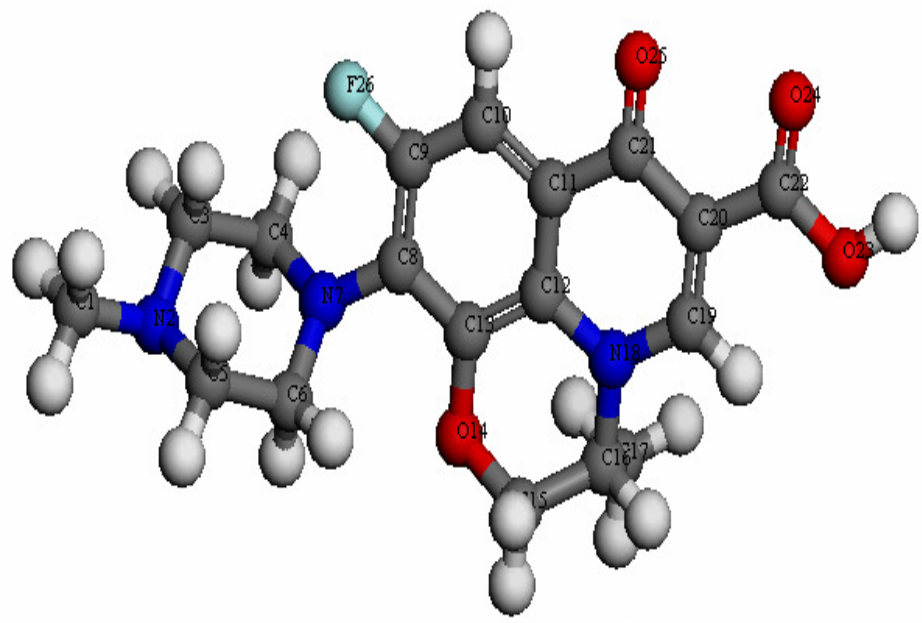

Figure 2. Optimized structure of thebenzoxazin derivative molecule

\section{Chemical reactivity}

The results of the quantum chemical parameters are presented in Table 1. $\mathrm{E}_{\mathrm{HOMO}}$ indicates the ability of the molecules to donate electron to an appropriate acceptor with the empty molecular orbital and $\mathrm{E}_{\mathrm{LUMO}}$ indicates the ability to accept electrons. The lower the $\mathrm{E}_{\mathrm{LUMO}}$, the more the ability of the molecule to accept electrons, while the higher the value of the $\mathrm{E}_{\mathrm{HOMO}}$, the more the ability of the molecules to offer electrons to unoccupied $d$-orbital of metal surface and the greater the inhibition efficiency ${ }^{19}$. The calculated quantum chemical parameters obtained from DFT analysis showa relatively high $\mathrm{E}_{\mathrm{HOMO}}$ value and the molecule is expected to have a high inhibition efficiency. The expectation is in good agreement with the experimental results reported ${ }^{14}$.

Table 1. Calculated quantum chemical parameters of the studied compound

\begin{tabular}{cccccccccc}
\hline $\begin{array}{c}E_{\text {номо }} \\
\mathrm{eV}\end{array}$ & $\begin{array}{c}E_{\text {LUMO }}, \\
\mathrm{eV}\end{array}$ & $\begin{array}{c}\Delta E, \\
\mathrm{eV}\end{array}$ & $\begin{array}{c}I P, \\
\mathrm{eV}\end{array}$ & $\begin{array}{c}E A, \\
\mathrm{eV}\end{array}$ & $\chi, \mathrm{eV}$ & $\begin{array}{c}\eta, \\
\mathrm{eV}\end{array}$ & $\begin{array}{c}\sigma, \\
\mathrm{eV}^{-1}\end{array}$ & $\begin{array}{c}\mu, \\
\text { debyes }\end{array}$ & $\omega$ \\
\hline-4.708 & -2.204 & 2.504 & 4.708 & 2.204 & 3.456 & 1.252 & 0.798 & 8.955 & 4.769 \\
\hline
\end{tabular}

The application of energy gap $\Delta E$ can also be used to predict the inhibition efficiency of a compound. $\Delta E$ is also used to develop a theoretical model for explaining the structure and confirmation barrier in many molecular systems. Therefore, the smaller the value of the energy gap of a compound, the higher the inhibition efficiency. The value of the energy gap $\Delta E$ is suggests that the studied molecules may be adsorbed relatively well and they function well as an inhibitor. The value of $\Delta E$ is calculated from the expression ${ }^{20}$ given in equation 5 . 


$$
\Delta E=E_{L U M O}-E_{\text {HOMO }}
$$

Ionization potential $(I P)$ is the maximum energy necessary to remove an electron from a many electron atom in gas phase, whereas electron affinity $(E A)$ is the energy released when an electron attaches to a gas phase atom. Ionization potential $(I P)$ is related to $E_{\mathrm{HOMO}}$ while the electron affinity is related to $E_{\mathrm{LUMO}}$ according to equation 6 and 7 respectively.

$$
\begin{aligned}
& I P=-E_{\text {номо }} \\
& E A=-E_{\text {LUMO }}
\end{aligned}
$$

Generally, high ionization potential is indicated in greater inhibition efficiency, while low electron affinity reflects reduced inhibition efficiency. The ionization potential $(I P)$ and the electron affinity $(E A)$ for the studied molecule is shown in Table 1. Electronegativity gives the power of an electron or group of atoms to attract electrons toward itself, thus Koopman's theorem was used to estimate the electronegativity of the studied ${ }^{13,20}$ compounds using equation 8 .

$$
x=-\frac{1}{2}\left(E_{\text {Номо }}+E_{L U M O}\right)
$$

The higher the value of $\chi$ the more effective the inhibitor and the lower $\chi$ the less significant the inhibitor. From the results listed in Table 1, it is observed that the value of electronegativity $\chi$ assigned to the studied compound confirms a greater significance of the studied compound to function as an inhibitor of steel corrosion in acid media.This result corroborates to the values of inhibition efficiency ${ }^{14}$. Global hardness $\eta$ measures the resistance of an atom to charge transfer whereas global softness $\sigma$ describes the capacity of an atom or group of atom to receive electrons ${ }^{21}$. The expressions for global hardness $\eta$ and global softness $\sigma$ are given in equation 9 and 10 respectively.

$$
\begin{aligned}
& \eta=-\frac{1}{2}\left(E_{\text {номо }}+E_{L U M O}\right) \\
& \sigma=-\frac{1}{\eta}
\end{aligned}
$$

A hard molecule requires a large $\Delta E$ and a soft molecule requires a small $\Delta E$. Soft molecules could therefore easily offer electrons to an acceptor system that make them more reactive than hard molecules. Furthermore, adsorption may occur at the point of a molecule where absolute softness $(\sigma)$ is high ${ }^{22}$. Table 1 reveals the value of both the global softness and the global hardness establishing that the compound is an excellent inhibitor. Dipole moment $(\mu)$ is another index that is often used for the prediction of corrosion inhibition process. It is the measure of polarity in a bond, and is related to the distribution of electrons in a molecule. Therefore inhibitors with high dipole moment form strong dipole-dipole interaction with the metal resulting in a strong adsorption on the surface of the metal thus leading to a greater inhibition efficiency ${ }^{22}$. It is observed from Table 1 that the dipole moment $(\mu)$ of the studied molecule shows a relatively high value of dipole moment, implying that the compound is expected to have a significant inhibition process. Global electrophilicity index $(\omega)$ is estimated by using both electrophilicity and chemical hardness parameters as expressed in equation 11.

$$
\omega=\frac{x^{2}}{2 \eta}
$$


A high value of electrophilicity describes a good electrophile while a small value of electrophilicity describes a good nucleophile. The results presented in Table 1 show that the investigated compound exhibits a reasonable value of electrophilicity describing the compound as a good electrophile.

Figure 3 presents a plot showing the variation of the quantum parameter $\mathrm{E}_{\mathrm{HOMO}}$ with experimental inhibition efficiency (\%IE) obtained from earlier report ${ }^{14}$. The plots revealed a strong correlation $\mathrm{R}^{2}=0.998$ between both the experimental inhibition efficiency and $E_{\text {Hомо }}$.

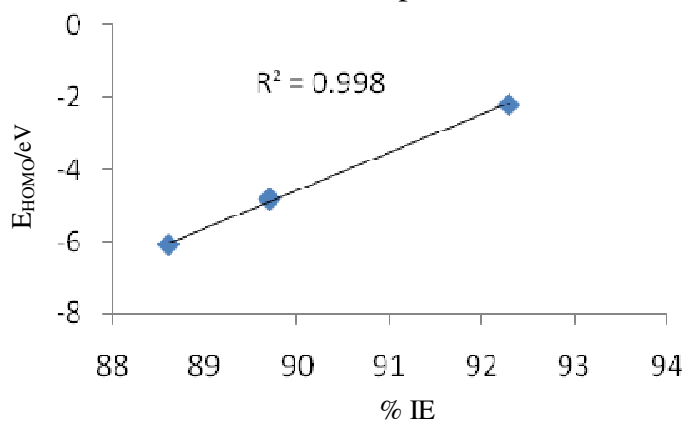

Figure 3. Variation of $E_{\text {Hомо }}$ with experimental inhibition efficiency for benzoxazin derivative

\section{Local reactivity}

Using the finite difference approximation, Fukui functions can be expressed as follows; $\mathrm{f}_{\mathrm{x}}^{+}=\mathrm{q}_{(\mathrm{N}+1)}-\mathrm{q}_{(\mathrm{N})}$ representing the change in electron density $\mathrm{q}$ at atom $\mathrm{N}$ upon addition of electron to the system, $\mathrm{f}_{\mathrm{x}}{ }^{-}=\mathrm{q}_{(\mathrm{N})}-\mathrm{q}_{(\mathrm{N}-1)}$ representing the change in electron density $\mathrm{q}$ at atom $\mathrm{N}$ upon removal of electron from the system, $\mathrm{q}_{(\mathrm{N}+1)}, \mathrm{q}_{(\mathrm{N})}$ and $\mathrm{q}_{(\mathrm{N}-1)}$ are the Mulliken charges of the atom with $\mathrm{N}+1, \mathrm{~N}$ and $\mathrm{N}-1$ electrons ${ }^{16} . \mathrm{F}_{\mathrm{x}}{ }^{+}$is the Fukui function for nucleophilic attack and $\mathrm{f}_{\mathrm{x}}{ }^{-}$is the Fukui function for electrophilic attack. From the simplest molecular orbital theory model, additional electrons would occupy the lowest unoccupied molecular orbital (LUMO) and ionization electrons would be removed from the highest occupied molecular orbital (HOMO). It is expected that $\mathrm{f}_{\mathrm{x}}{ }^{+}$and $\mathrm{f}_{\mathrm{x}}{ }^{-}$are related to LUMO and HOMO respectively ${ }^{19}$. Atomic charges and condensed Fukui functions can be used to analyze the local reactivity of a molecules and to distinct each part of the molecule on the basis of its distinct chemical ehavior due to the presence of dissimilar functional groups. The Fukui function is motivated by the fact that if an electron $\delta$ is transferred to an N-electron molecule, it also tends to share out electrons so as to reduce the energy of the resulting $\mathrm{N}+\delta$ electron structure ${ }^{12}$. Thus, the preferred sites for an attack by electrophilic and nucleophilic agents are observed at the positions where the values of Fukui $\mathrm{f}^{-}$and $\mathrm{f}^{+}$respectively is a maximum ${ }^{1,19}$. An atom with the highest positive charge is the preferred site for electrophilic attack while the preferred site for nucleophilic attack is at an atom with the highest negative charge ${ }^{13}$. The local reactivity is illustrated in Figure 4. The first four maximum values of Fukui function (f) of the studied compound are recorded as 0.782, 0.109, 0.031 and 0.029 as shown in bold font in Table 2, signifying that electrophilic attack occurs at the bond $\mathrm{C}_{22}=$ $\mathrm{O}_{24}, \mathrm{C}_{5}-\mathrm{N}_{2}, \mathrm{C}_{22}-\mathrm{O}_{23}$ and $\mathrm{C}_{11}-\mathrm{C}_{12}$ while nucleophilic attack occurs at $\mathrm{N}_{18}-\mathrm{C}_{12}, \mathrm{C}_{16}-\mathrm{C}_{17}$, $\mathrm{C}_{4}-\mathrm{N}_{7}$ and $\mathrm{C}_{6}-\mathrm{C}_{5}$ having $\mathrm{f}^{+}$values of $-0.128,-0.031,-0.017$ and -0.016 respectively. Also, since the charge on atoms $\mathrm{O}_{23}, \mathrm{O}_{14}, \mathrm{O}_{25}$, and $\mathrm{O}_{24}$ were high, electrophilic attack is expected to occur at $\mathrm{C}_{20}-\mathrm{C}_{22}, \mathrm{O}_{14}-\mathrm{C}_{15}, \mathrm{C}_{22}=\mathrm{O}_{24}$ and $\mathrm{C}_{22}-\mathrm{O}_{23}$. Since shorter bond lengths are less reactive than longer bond lengths and multiple bonds are more reactive than a single bond, 
the bond length of the molecules were calculated and examined for their degree of reactivity. The bond lengths between $\mathrm{C}_{16}-\mathrm{C}_{17}, \mathrm{C}_{6}-\mathrm{C}_{5}, \mathrm{C}_{3}-\mathrm{C}_{4}$ and $\mathrm{C}_{16}-\mathrm{N}_{18}$ were $1.539 \AA, 1.533 \AA$, $1.530 \AA$ and $1.528 \AA$ respectively. These properties are shown in Table 2 .

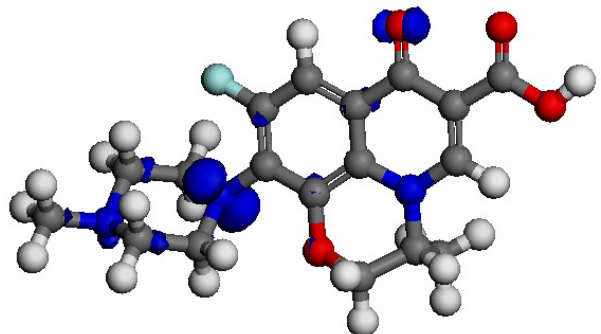

(a) Fukui (f)

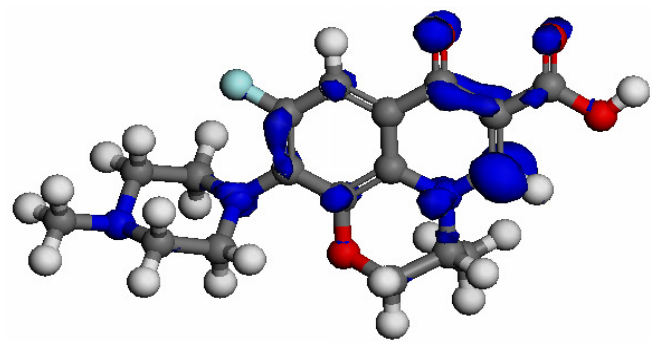

(b) Fukui $\left(\mathrm{f}^{+}\right)$

Figure 4. (a) Electrophilic Fukui function $\mathrm{f}^{-}$and (b) nucleophilic Fukui function $\mathrm{f}^{+}$of benzoxazin derivative

Table 2.Calculated values of bond length, atomic charge, DFT Fukui (f) and Fukui (f $f^{+}$) for the studied compound

\begin{tabular}{cccccc}
\hline Atom & Bond & Length & Charge & Fukui f & Fukui $\left(\mathrm{f}^{+}\right)$ \\
\hline $\mathrm{C}_{1}$ & $\mathrm{C}_{1}-\mathrm{N}_{2}$ & 1.470 & -0.262 & -0.029 & -0.014 \\
$\mathrm{~N}_{2}$ & $\mathrm{~N}_{2}-\mathrm{C}_{3}$ & 1.477 & -0.324 & 0.023 & 0.002 \\
$\mathrm{C}_{3}$ & $\mathrm{C}_{3}-\mathrm{C}_{4}$ & $\mathbf{1 . 5 3 0}$ & -0.099 & -0.023 & -0.004 \\
$\mathrm{C}_{4}$ & $\mathrm{C}_{4}-\mathrm{N}_{7}$ & 1.468 & -0.051 & -0.033 & $\mathbf{- 0 . 0 1 7}$ \\
$\mathrm{C}_{5}$ & $\mathrm{~N}_{7}-\mathrm{C}_{6}$ & 1.467 & -0.099 & -0.021 & 0.002 \\
$\mathrm{C}_{6}$ & $\mathrm{C}_{6}-\mathrm{C}_{5}$ & $\mathbf{1 . 5 3 3}$ & -0.065 & -0.035 & $\mathbf{- 0 . 0 1 6}$ \\
$\mathrm{N}_{7}$ & $\mathrm{C}_{5}-\mathrm{N}_{2}$ & 1.477 & -0.349 & $\mathbf{0 . 1 0 9}$ & 0.017 \\
$\mathrm{C}_{8}$ & $\mathrm{~N}_{7}-\mathrm{C}_{8}$ & 1.451 & 0.129 & -0.001 & 0.022 \\
$\mathrm{C}_{9}$ & $\mathrm{C}_{8}=\mathrm{C}_{9}$ & 1.413 & 0.321 & 0.024 & 0.037 \\
$\mathrm{C}_{10}$ & $\mathrm{C}_{9}-\mathrm{C}_{10}$ & 1.391 & -0.096 & 0.016 & 0.040 \\
$\mathrm{C}_{11}$ & $\mathrm{C}_{11}-\mathrm{C}_{12}$ & 1.402 & -0.063 & $\mathbf{0 . 0 2 9}$ & -0.004 \\
$\mathrm{C}_{12}$ & $\mathrm{C}_{12}=\mathrm{C}_{13}$ & 1.399 & 0.122 & 0.018 & 0.004 \\
$\mathrm{C}_{13}$ & $\mathrm{C}_{13}-\mathrm{O}_{14}$ & 1.415 & 0.232 & -0.041 & 0.049 \\
$\mathrm{O}_{14}$ & $\mathrm{O}_{14}-\mathrm{C}_{15}$ & 1.415 & $\mathbf{- 0 . 6 0 5}$ & 0.009 & 0.023 \\
$\mathrm{C}_{15}$ & $\mathrm{C}_{15}-\mathrm{C}_{16}$ & 1.436 & 0.031 & -0.019 & -0.013 \\
$\mathrm{C}_{16}$ & $\mathrm{C}_{16}-\mathrm{C}_{17}$ & $\mathbf{1 . 5 3 9}$ & 0.022 & -0.014 & $\mathbf{- 0 . 0 3 1}$ \\
$\mathrm{C}_{17}$ & $\mathrm{C}_{16}-\mathrm{N}_{18}$ & $\mathbf{1 . 5 2 8}$ & -0.334 & -0.006 & -0.011 \\
$\mathrm{~N}_{18}$ & $\mathrm{~N}_{18}-\mathrm{C}_{12}$ & 1.466 & -0.359 & 0.001 & $\mathbf{- 0 . 1 2 8}$ \\
$\mathrm{C}_{19}$ & $\mathrm{~N}_{18}-\mathrm{C}_{19}$ & 1.442 & -0.016 & 0.016 & 0.013 \\
$\mathrm{C}_{20}$ & $\mathrm{C}_{19}=\mathrm{C}_{20}$ & 1.345 & 0.025 & 0.011 & 0.020 \\
$\mathrm{C}_{21}$ & $\mathrm{C}_{20}-\mathrm{C}_{21}$ & 1.482 & 0.292 & 0.018 & 0.047 \\
$\mathrm{C}_{22}$ & $\mathrm{C}_{21}-\mathrm{C}_{11}$ & 1.477 & 0.533 & 0.018 & 0.036 \\
$\mathrm{O}_{23}$ & $\mathrm{C}_{20}-\mathrm{C}_{22}$ & 1.481 & $\mathbf{- 0 . 6 7 1}$ & 0.013 & 0.018 \\
$\mathrm{O}_{24}$ & $\mathrm{C}_{22}-\mathrm{O}_{23}$ & 1.393 & $\mathbf{- 0 . 3 7 9}$ & $\mathbf{0 . 0 3 1}$ & 0.063 \\
$\mathrm{O}_{25}$ & $\mathrm{C}_{22}=\mathrm{O}_{24}$ & 1.217 & $\mathbf{- 0 . 3 9 6}$ & $\mathbf{0 . 7 8 2}$ & 0.081 \\
$\mathrm{~F}_{26}$ & $\mathrm{C}_{21}=\mathrm{O}_{25}$ & 1.219 & -0.649 & 0.022 & 0.035 \\
\hline & & & & &
\end{tabular}

Mechanism of Inhibition

Corrosion inhibition mechanism in acidic medium is based on the adsorption of inhibitor on the metal surface. The process of adsorption is influenced by the nature and charge of the metal, 
the chemical structure of the inhibitor and the type of aggressive electrolyte. The inhibitor molecules are adsorbed over the metal surface by blocking the active sites in which direct acid attack, thereby protecting the metal from corrosion ${ }^{23}$. The structure of the studied compound has an oxygen heteroatom and $\mathrm{C}=\mathrm{O}$ bond, therefore inhibition of the corrosion of carbon steel of the studied molecule may be attributed to the adsorption of the studied molecule through the $\mathrm{C}=\mathrm{O}$ center, which is regarded as the center of adsorption onto the metal surface. The adsorption creates a barrier to mass and charge transfer and thus isolates metal from further attack of the corrosive anions ${ }^{19}$. The inhibitors may then combine with freshly generated $\mathrm{Fe}^{2+}$ ions on the metal surface forming an iron-inhibitor complex as shown in equation 13 and Figure 5.

$$
\begin{aligned}
& \mathrm{Fe} \rightarrow \mathrm{Fe}^{2+}+2 e^{-} \\
& \mathrm{Fe}+\text { inhibitor }{ }_{a d s} \rightarrow[\mathrm{Fe}-\text { inhibitor }]_{a d s}^{2+}
\end{aligned}
$$

Figure 5 shows a nucleophilic attack on the partially positive carbon atom and the intermediate of full negative charge onoxygen atom. The oxygen then becomes protonated to yield an iron-inhibitor complex. The protonated oxygen atoms are the atoms that facilitate adsorption onto the metal surface. From the resulting complex, it may be suggested that the studied compound inhibits carbon steel corrosion in acidic medium. The adsorption of the inhibitor on the metal surface therefore reduces the surface area available for corrosion ${ }^{9}$.

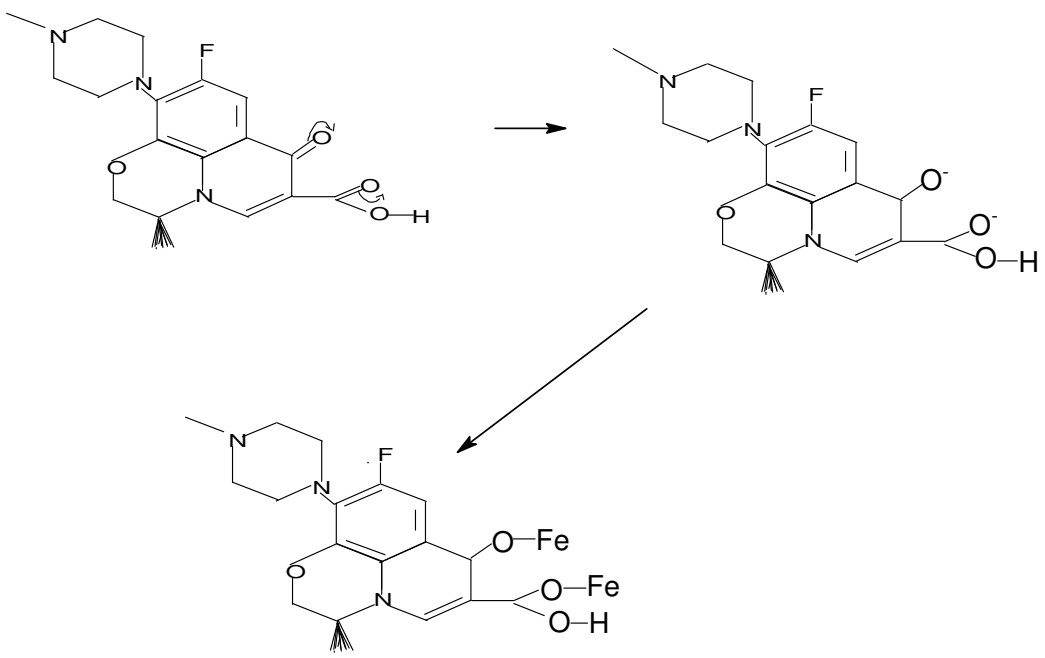

Figure 5. Inhibition mechanism of carbon steel corrosion in $2 \mathrm{M} \mathrm{HCl}$ for benzoxazin derivative

\section{Conclusion}

Quantum chemical study is adequately sufficient to predict the structure and molecule suitability of an inhibitor. Quantum chemical calculations reveal that the prefer site forelectrophilic and nucleophilic attack resides at the bonds $\mathrm{C}_{22}=\mathrm{O}_{24}, \mathrm{C}_{5}-\mathrm{N}_{2}, \mathrm{C}_{22}-\mathrm{O}_{23}$ and $\mathrm{C}_{11}-\mathrm{C}_{12}$ and at $\mathrm{N}_{18}-\mathrm{C}_{12}, \mathrm{C}_{16}-\mathrm{C}_{17}, \mathrm{C}_{4}-\mathrm{N}_{7}$ and $\mathrm{C}_{6}-\mathrm{C}_{5}$ respectively. In addition, based on the relatively high charge on atoms $\mathrm{O}_{23}, \mathrm{O}_{14}, \mathrm{O}_{25}$, and $\mathrm{O}_{24}$, electrophilic attack is expected to occur at $\mathrm{C}_{20}-\mathrm{C}_{22}, \mathrm{O}_{14}-\mathrm{C}_{15}, \mathrm{C}_{22}=\mathrm{O}_{24}$ and $\mathrm{C}_{22}-\mathrm{O}_{23}$. Benzoxazin derivative is a good corrosion inhibitor for carbon steel in acidic environment. The inhibitor possesses heteroatoms and functional groups that facilitate easy adsorption on the surface of steel. 


\section{Acknowlegdement}

The authors are grateful to the Corrosion and Electrochemistry Research Laboratory (CERLab.), Dept. of Pure and Applied Chemistry, UNICAL for research support.

\section{References}

1. Eddy N O, Odoemelam S A, Ogoko E C and Ita B I, Port Electrochim Acta, 2010, 28(1), 15-26; DOI:10.4152/pea.201001015

2. Okafor P C, Ebenso E E and Ekpe U J, Int J Electrochem Sci., 2010, 5, 978-993.

3. Ikpi M E, Abeng F E and Obono O E, World News Nat Sci., 2017, 9, 52-61.

4. $\quad$ Akpan I A and Offiong N O, Int J Chem Mater Res., 2014, 2(3), 23-29.

5. AkpanI A and Offiong N O, Chem Process Eng Res., 2014, 26, 20-23.

6. Attia E M, J Basic Appl Chem., 2015, 5(1), 1-15.

7. Abdel-Hameed R S, Ismail E A, Abu-Nawwas A H and Al-Shafey H I, Int J Electrochem Sci., 2015, 10, 2098-2109.

8. Karthikeyan S, Jeeva P A and Raja K, Int J ChemTech Res., 2015, 8(3), 1391-1395.

9. Abdullatef O A, J Adv Chem., 2015, 11(5), 3642- 3655.

10. Siaka A A, Eddy N O, Idris S O, Magaji L, Garba Z N and Shabanda I S, Int J Modern Chem., 2013, 4(1), 1-10.

11. Naqvi I, Saleemi A R and Naveed S, Int J Electrochem Sci., 2011, 6, 146-161.

12. Eddy N O, Stoyanov S R and Ebenso E E, Int J Electrochem Sci., 2010, 5, 1127-1150.

13. Ameh P O, Eddy N O and Koha P U, Chem Sci J., 2015, 6(3), 100; DOI: $10.4172 / 2150-3494.1000100$

14. Ikpi M E and Abeng F E, Int J Sci Res., 2017, 6(7), 623-628.

15. Mohammed M E and Taha K K, Researcher, 2012, 4(11), 92-97.

16. Obot I B, In: Developments in corrosion protection, In Tech; DOI:10.5772/57245

17. Young D C, Computational Chemistry: A practical Guide for Applying Techniques to Real-World Problems; John Wiley and Son Inc.: New York, 2001.

18. Jensen F, Introduction to Computer Chemistry; John Wiley and Sons Inc.: New York, 1999.

19. Fouda A S, Bekheit G E and El-Sherbari M W, J Bio Tribo-Corros., 2016, 2, 11; DOI:10.1007/s40735-016-0039-y

20. Shahabi S, Norouzi P and Ganjali M R, Int J Electrochem Sci., 2015, 10, 2646-2662.

21. Kabanda M M, Murulana L C, Ozcan M, Karadag F, Dehri I, Obot I B and Ebenso E E, Int J Electrochem Sci., 2012, 7, 5035-5056.

22. Elmsellem H, Nacer H, Halaimia F, Aouniti A, Lakehal I, Chetouani A, Deyab S S, Warad I, Touzani R and Hammonti B, Int J Electrochem Sci., 2014, 9, 5328-5351.

23. Karthikeyan S and Kumar S H, J Mater Environ Sci., 2012, 3(5), 925-934. 


\title{
Theoretical Study on the Structural Effect of Benzoxazin Derivative as Corrosion Inhibitor for Carbon Steel in Acid Media
}

\author{
MAGDALENE EDET IKPI* and FIDELIS EBUNTA ABENG \\ Corrosion and Electrochemistry Research Laboratory, Department of Pure and Applied \\ Chemistry, University of Calabar, P.M.B. 1115, Calabar-Nigeria \\ meikpi@unical.edu.ng
}

Received 8 July 2017 / Accepted 20 July 2017

\begin{abstract}
Drug-based compounds are eco-friendly, nontoxic, inexpensive and easily accessible source of material which can consecutively be used as corrosion inhibitor for carbon steel in acid media. The effect of benzoxaxin derivative, a drug-based compound was investigated by theoretical advance study. The energy of the highest occupied molecular orbital (EHOMO), energy of the lowest unoccupied molecular orbital (ELUMO), the energy gap $(\Delta \mathrm{E})$, dipole moment $(\mu)$ mullikencharge of heteroatoms, ionization potential (IP), electron affinity (EA), electronegativity $(\chi)$, global hardness $(\eta)$ and global softness $(\sigma)$ were calculated and interpreted. Quantum chemical calculations revealed the adsorption of the molecules on the metal surface.
\end{abstract}

Keywords: DFT, Corrosion inhibition, Adsorption mechanism, Benzoxazin

\section{Introduction}

Levofloxacin is an antibiotic drug, derived from benzoxazin compound. Benzoxazin compound constitutes organic material and mostly having heterocyclic atoms such as $\mathrm{N}, \mathrm{O}$ and $\mathrm{S}$ either in the aromatic or long carbon chain. Such systemic arrangement has been reported as effective inhibitors ${ }^{1}$. These inhibitors have extended $\pi$-electron systems and functional groups, such as $-\mathrm{C}=\mathrm{C}-,-\mathrm{OH}$ and $-\mathrm{NH}_{2}$. The functional groups provide electrons that facilitate adsorption of the inhibitors on the metal surface ${ }^{2}$. Some drug-based compounds have been reported as good corrosion inhibitors in acidic media ${ }^{3-12}$. Corrosion inhibitors promote film formation on the metal surface through transfer of electrons from the organic compounds to the metal, forming a donor-acceptor bond during adsorption process ${ }^{1}$. In such adsorption, the metal functions as an electrophile while the inhibitor acts as a nucleophile $^{13}$. Experimental investigation of the action of levofloxacin drug, a derivative of benzoxazin compound on the corrosion inhibition of carbon steel in $2 \mathrm{M} \mathrm{HCl}$ solution has been reported ${ }^{14}$. The experimental means were useful in explaining the inhibition mechanism but they are often expensive and time consuming. Advances in computer hardware and in theoretical chemistry have brought high performance computing and graphical 
tools within the reach of many academic and industrial laboratory ${ }^{15}$. Currently, corrosion publications containing quantum chemical calculations are used to explore the electronic properties of inhibitors. The energy of the frontier molecular orbitals $\left(\mathrm{E}_{\mathrm{HOMO}}\right.$ and $\left.\mathrm{E}_{\mathrm{LUMO}}\right)$, energy gap $(\Delta E)$, charge on the reactive center $\left(\mathrm{f}^{+}\right.$and $\left.\mathrm{f}\right)$, dipole moment $(\mu)$, global hardness $(\eta)$ and global softness $(\sigma)$ etc., have been investigated to achieve the appropriate correlation.

\section{Method of calculation}

There are various quantum-based advances that have been functional to organic materials design including; Hatree-fock, Moller-plesset, coupled cluster and semi empirical methods. Though the most fashionable organic material design and calculation of chemical reactivity has been density functional theory (DFT), the main reason for its popularity has been the relative accuracy with significantly lower computational cost compared to some of the other methods listed above. DFT centers on the electron density $P(r)$ itself as the carrier of all information in the molecular or atomic ground state rather than on the single electron wave function ${ }^{16}$. Since the electron density arises from the collective contribution of all electrons, the ground state total energy for an $N$-electron system is based on DFT given in terms of threedimensional ground-state electronic density $P(r)$ and the external potential $V(r)$ in the form ${ }^{16,17}$;

$$
E(p)=F(p)+\int P(r) V(r) d r
$$

Where $E(p)$ is the kinetic energy functional, $F(p)$ is universal functional of Hohenbergekohn given by the sum of the electronic kinetic energy functional while equation 2 guarantees the proper normalization of the electron density.

$$
N=\int P(r) d r
$$

A general form of the DFT expression is shown in equation 3 according to literature ${ }^{16-18}$,

$$
E_{D F T}(p)=T_{s}(p)+E_{n e}(p)+J(p)+E_{x c}(p)
$$

Where $T_{\mathrm{s}}$ refers to the kinetic energy functional (s indicates that the kinetic energy is obtained from a slater determinant), $E_{n e}$ the electron nuclear attraction functional, $J$ the coulomb part of the electron-electron repulsion functional and $E_{x c}$ the exchange correlation functional. Each of these terms depend on the electron density $p$ and is indicated by the symbol $p$ in brackets following each term. Since the exchange correlation energy functional is unknown, approximate solutions are obtained using the Kohn-Sham (KS) orbitals. These differ from other kinds of orbitals primarily on the basis that the sum of the squares of the occupied KS orbitals is the true electron density of the system ${ }^{16}$. The solution of the Euler-Langrange equation which corresponds to the minimization of the energy given in equation 1 together with the consideration of equation 2 allows for the ground-state electronic density to be calculated as;

$$
\mu=\left[\frac{\delta E}{\delta P(r) v}\right]=V(r)+\frac{\delta F}{\delta P(r)}
$$

Where $\mu$ is the undetermined Langrange multiplier representing the chemical potential that measures the escaping tendency of the electrons from a system ${ }^{16}$. DFT was performed with the aid of Gaussian 03 software suite to provide a complete geometry optimization.

\section{Results and Discussion}

The chemical structure of the compound under study is shown in Figure 1. The optimized molecular structure of the investigated compound using Backe's three parameter hybrid functional and Lee-Yang-Paar correlation functional (B3LYP) is shown in Figure 2. 
<smiles>C[C@H]1COc2c(N3CCN(C)CC3)c(F)cc3c(=O)c(C(=O)O)cn1c23</smiles>

Figure 1. Chemical structure of benzoxazin derivative

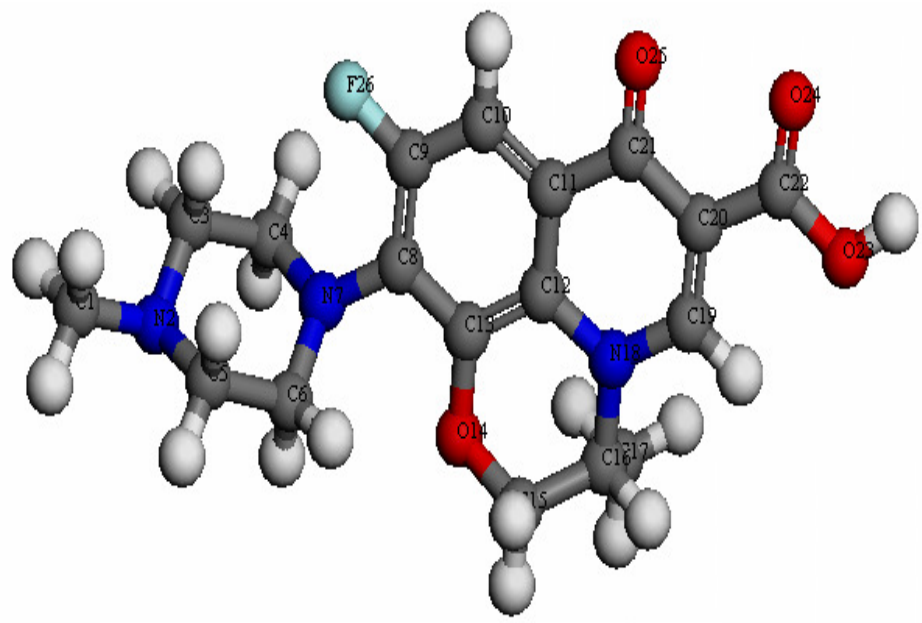

Figure 2. Optimized structure of thebenzoxazin derivative molecule

\section{Chemical reactivity}

The results of the quantum chemical parameters are presented in Table 1. $\mathrm{E}_{\mathrm{HOMO}}$ indicates the ability of the molecules to donate electron to an appropriate acceptor with the empty molecular orbital and $\mathrm{E}_{\mathrm{LUMO}}$ indicates the ability to accept electrons. The lower the $\mathrm{E}_{\mathrm{LUMO}}$, the more the ability of the molecule to accept electrons, while the higher the value of the $\mathrm{E}_{\mathrm{HOMO}}$, the more the ability of the molecules to offer electrons to unoccupied $d$-orbital of metal surface and the greater the inhibition efficiency ${ }^{19}$. The calculated quantum chemical parameters obtained from DFT analysis showa relatively high $\mathrm{E}_{\mathrm{HOMO}}$ value and the molecule is expected to have a high inhibition efficiency. The expectation is in good agreement with the experimental results reported ${ }^{14}$.

Table 1. Calculated quantum chemical parameters of the studied compound

\begin{tabular}{cccccccccc}
\hline $\begin{array}{c}E_{\text {номо }} \\
\mathrm{eV}\end{array}$ & $\begin{array}{c}E_{\text {LUMO }}, \\
\mathrm{eV}\end{array}$ & $\begin{array}{c}\Delta E, \\
\mathrm{eV}\end{array}$ & $\begin{array}{c}I P, \\
\mathrm{eV}\end{array}$ & $\begin{array}{c}E A, \\
\mathrm{eV}\end{array}$ & $\chi, \mathrm{eV}$ & $\begin{array}{c}\eta, \\
\mathrm{eV}\end{array}$ & $\begin{array}{c}\sigma, \\
\mathrm{eV}^{-1}\end{array}$ & $\begin{array}{c}\mu, \\
\text { debyes }\end{array}$ & $\omega$ \\
\hline-4.708 & -2.204 & 2.504 & 4.708 & 2.204 & 3.456 & 1.252 & 0.798 & 8.955 & 4.769 \\
\hline
\end{tabular}

The application of energy gap $\Delta E$ can also be used to predict the inhibition efficiency of a compound. $\Delta E$ is also used to develop a theoretical model for explaining the structure and confirmation barrier in many molecular systems. Therefore, the smaller the value of the energy gap of a compound, the higher the inhibition efficiency. The value of the energy gap $\Delta E$ is suggests that the studied molecules may be adsorbed relatively well and they function well as an inhibitor. The value of $\Delta E$ is calculated from the expression ${ }^{20}$ given in equation 5 . 


$$
\Delta E=E_{L U M O}-E_{\text {HOMO }}
$$

Ionization potential $(I P)$ is the maximum energy necessary to remove an electron from a many electron atom in gas phase, whereas electron affinity $(E A)$ is the energy released when an electron attaches to a gas phase atom. Ionization potential $(I P)$ is related to $E_{\mathrm{HOMO}}$ while the electron affinity is related to $E_{\mathrm{LUMO}}$ according to equation 6 and 7 respectively.

$$
\begin{aligned}
& I P=-E_{\text {номо }} \\
& E A=-E_{\text {LUMO }}
\end{aligned}
$$

Generally, high ionization potential is indicated in greater inhibition efficiency, while low electron affinity reflects reduced inhibition efficiency. The ionization potential $(I P)$ and the electron affinity $(E A)$ for the studied molecule is shown in Table 1. Electronegativity gives the power of an electron or group of atoms to attract electrons toward itself, thus Koopman's theorem was used to estimate the electronegativity of the studied ${ }^{13,20}$ compounds using equation 8 .

$$
x=-\frac{1}{2}\left(E_{\text {Номо }}+E_{L U M O}\right)
$$

The higher the value of $\chi$ the more effective the inhibitor and the lower $\chi$ the less significant the inhibitor. From the results listed in Table 1, it is observed that the value of electronegativity $\chi$ assigned to the studied compound confirms a greater significance of the studied compound to function as an inhibitor of steel corrosion in acid media.This result corroborates to the values of inhibition efficiency ${ }^{14}$. Global hardness $\eta$ measures the resistance of an atom to charge transfer whereas global softness $\sigma$ describes the capacity of an atom or group of atom to receive electrons ${ }^{21}$. The expressions for global hardness $\eta$ and global softness $\sigma$ are given in equation 9 and 10 respectively.

$$
\begin{aligned}
& \eta=-\frac{1}{2}\left(E_{\text {номо }}+E_{L U M O}\right) \\
& \sigma=-\frac{1}{\eta}
\end{aligned}
$$

A hard molecule requires a large $\Delta E$ and a soft molecule requires a small $\Delta E$. Soft molecules could therefore easily offer electrons to an acceptor system that make them more reactive than hard molecules. Furthermore, adsorption may occur at the point of a molecule where absolute softness $(\sigma)$ is high ${ }^{22}$. Table 1 reveals the value of both the global softness and the global hardness establishing that the compound is an excellent inhibitor. Dipole moment $(\mu)$ is another index that is often used for the prediction of corrosion inhibition process. It is the measure of polarity in a bond, and is related to the distribution of electrons in a molecule. Therefore inhibitors with high dipole moment form strong dipole-dipole interaction with the metal resulting in a strong adsorption on the surface of the metal thus leading to a greater inhibition efficiency ${ }^{22}$. It is observed from Table 1 that the dipole moment $(\mu)$ of the studied molecule shows a relatively high value of dipole moment, implying that the compound is expected to have a significant inhibition process. Global electrophilicity index $(\omega)$ is estimated by using both electrophilicity and chemical hardness parameters as expressed in equation 11.

$$
\omega=\frac{x^{2}}{2 \eta}
$$


A high value of electrophilicity describes a good electrophile while a small value of electrophilicity describes a good nucleophile. The results presented in Table 1 show that the investigated compound exhibits a reasonable value of electrophilicity describing the compound as a good electrophile.

Figure 3 presents a plot showing the variation of the quantum parameter $\mathrm{E}_{\mathrm{HOMO}}$ with experimental inhibition efficiency (\%IE) obtained from earlier report ${ }^{14}$. The plots revealed a strong correlation $\mathrm{R}^{2}=0.998$ between both the experimental inhibition efficiency and $E_{\text {Hомо }}$.

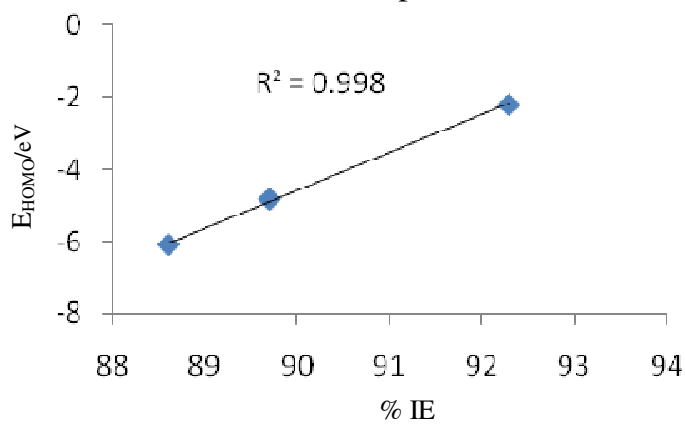

Figure 3. Variation of $E_{\text {Hомо }}$ with experimental inhibition efficiency for benzoxazin derivative

\section{Local reactivity}

Using the finite difference approximation, Fukui functions can be expressed as follows; $\mathrm{f}_{\mathrm{x}}^{+}=\mathrm{q}_{(\mathrm{N}+1)}-\mathrm{q}_{(\mathrm{N})}$ representing the change in electron density $\mathrm{q}$ at atom $\mathrm{N}$ upon addition of electron to the system, $\mathrm{f}_{\mathrm{x}}{ }^{-}=\mathrm{q}_{(\mathrm{N})}-\mathrm{q}_{(\mathrm{N}-1)}$ representing the change in electron density $\mathrm{q}$ at atom $\mathrm{N}$ upon removal of electron from the system, $\mathrm{q}_{(\mathrm{N}+1)}, \mathrm{q}_{(\mathrm{N})}$ and $\mathrm{q}_{(\mathrm{N}-1)}$ are the Mulliken charges of the atom with $\mathrm{N}+1, \mathrm{~N}$ and $\mathrm{N}-1$ electrons ${ }^{16} . \mathrm{F}_{\mathrm{x}}{ }^{+}$is the Fukui function for nucleophilic attack and $\mathrm{f}_{\mathrm{x}}{ }^{-}$is the Fukui function for electrophilic attack. From the simplest molecular orbital theory model, additional electrons would occupy the lowest unoccupied molecular orbital (LUMO) and ionization electrons would be removed from the highest occupied molecular orbital (HOMO). It is expected that $\mathrm{f}_{\mathrm{x}}{ }^{+}$and $\mathrm{f}_{\mathrm{x}}{ }^{-}$are related to LUMO and HOMO respectively ${ }^{19}$. Atomic charges and condensed Fukui functions can be used to analyze the local reactivity of a molecules and to distinct each part of the molecule on the basis of its distinct chemical ehavior due to the presence of dissimilar functional groups. The Fukui function is motivated by the fact that if an electron $\delta$ is transferred to an N-electron molecule, it also tends to share out electrons so as to reduce the energy of the resulting $\mathrm{N}+\delta$ electron structure ${ }^{12}$. Thus, the preferred sites for an attack by electrophilic and nucleophilic agents are observed at the positions where the values of Fukui $\mathrm{f}^{-}$and $\mathrm{f}^{+}$respectively is a maximum ${ }^{1,19}$. An atom with the highest positive charge is the preferred site for electrophilic attack while the preferred site for nucleophilic attack is at an atom with the highest negative charge ${ }^{13}$. The local reactivity is illustrated in Figure 4. The first four maximum values of Fukui function (f) of the studied compound are recorded as 0.782, 0.109, 0.031 and 0.029 as shown in bold font in Table 2, signifying that electrophilic attack occurs at the bond $\mathrm{C}_{22}=$ $\mathrm{O}_{24}, \mathrm{C}_{5}-\mathrm{N}_{2}, \mathrm{C}_{22}-\mathrm{O}_{23}$ and $\mathrm{C}_{11}-\mathrm{C}_{12}$ while nucleophilic attack occurs at $\mathrm{N}_{18}-\mathrm{C}_{12}, \mathrm{C}_{16}-\mathrm{C}_{17}$, $\mathrm{C}_{4}-\mathrm{N}_{7}$ and $\mathrm{C}_{6}-\mathrm{C}_{5}$ having $\mathrm{f}^{+}$values of $-0.128,-0.031,-0.017$ and -0.016 respectively. Also, since the charge on atoms $\mathrm{O}_{23}, \mathrm{O}_{14}, \mathrm{O}_{25}$, and $\mathrm{O}_{24}$ were high, electrophilic attack is expected to occur at $\mathrm{C}_{20}-\mathrm{C}_{22}, \mathrm{O}_{14}-\mathrm{C}_{15}, \mathrm{C}_{22}=\mathrm{O}_{24}$ and $\mathrm{C}_{22}-\mathrm{O}_{23}$. Since shorter bond lengths are less reactive than longer bond lengths and multiple bonds are more reactive than a single bond, 
the bond length of the molecules were calculated and examined for their degree of reactivity. The bond lengths between $\mathrm{C}_{16}-\mathrm{C}_{17}, \mathrm{C}_{6}-\mathrm{C}_{5}, \mathrm{C}_{3}-\mathrm{C}_{4}$ and $\mathrm{C}_{16}-\mathrm{N}_{18}$ were $1.539 \AA, 1.533 \AA$, $1.530 \AA$ and $1.528 \AA$ respectively. These properties are shown in Table 2 .

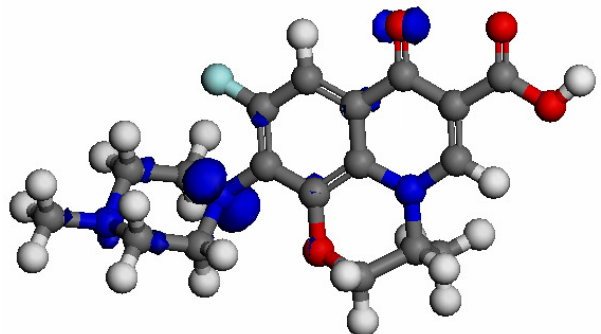

(a) Fukui (f)

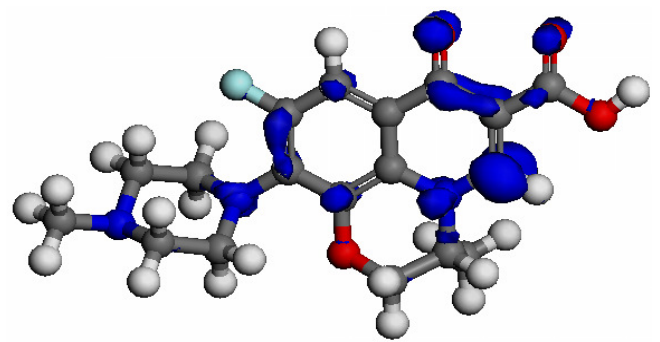

(b) Fukui $\left(\mathrm{f}^{+}\right)$

Figure 4. (a) Electrophilic Fukui function $\mathrm{f}^{-}$and (b) nucleophilic Fukui function $\mathrm{f}^{+}$of benzoxazin derivative

Table 2.Calculated values of bond length, atomic charge, DFT Fukui (f) and Fukui (f $f^{+}$) for the studied compound

\begin{tabular}{cccccc}
\hline Atom & Bond & Length & Charge & Fukui f & Fukui $\left(\mathrm{f}^{+}\right)$ \\
\hline $\mathrm{C}_{1}$ & $\mathrm{C}_{1}-\mathrm{N}_{2}$ & 1.470 & -0.262 & -0.029 & -0.014 \\
$\mathrm{~N}_{2}$ & $\mathrm{~N}_{2}-\mathrm{C}_{3}$ & 1.477 & -0.324 & 0.023 & 0.002 \\
$\mathrm{C}_{3}$ & $\mathrm{C}_{3}-\mathrm{C}_{4}$ & $\mathbf{1 . 5 3 0}$ & -0.099 & -0.023 & -0.004 \\
$\mathrm{C}_{4}$ & $\mathrm{C}_{4}-\mathrm{N}_{7}$ & 1.468 & -0.051 & -0.033 & $\mathbf{- 0 . 0 1 7}$ \\
$\mathrm{C}_{5}$ & $\mathrm{~N}_{7}-\mathrm{C}_{6}$ & 1.467 & -0.099 & -0.021 & 0.002 \\
$\mathrm{C}_{6}$ & $\mathrm{C}_{6}-\mathrm{C}_{5}$ & $\mathbf{1 . 5 3 3}$ & -0.065 & -0.035 & $\mathbf{- 0 . 0 1 6}$ \\
$\mathrm{N}_{7}$ & $\mathrm{C}_{5}-\mathrm{N}_{2}$ & 1.477 & -0.349 & $\mathbf{0 . 1 0 9}$ & 0.017 \\
$\mathrm{C}_{8}$ & $\mathrm{~N}_{7}-\mathrm{C}_{8}$ & 1.451 & 0.129 & -0.001 & 0.022 \\
$\mathrm{C}_{9}$ & $\mathrm{C}_{8}=\mathrm{C}_{9}$ & 1.413 & 0.321 & 0.024 & 0.037 \\
$\mathrm{C}_{10}$ & $\mathrm{C}_{9}-\mathrm{C}_{10}$ & 1.391 & -0.096 & 0.016 & 0.040 \\
$\mathrm{C}_{11}$ & $\mathrm{C}_{11}-\mathrm{C}_{12}$ & 1.402 & -0.063 & $\mathbf{0 . 0 2 9}$ & -0.004 \\
$\mathrm{C}_{12}$ & $\mathrm{C}_{12}=\mathrm{C}_{13}$ & 1.399 & 0.122 & 0.018 & 0.004 \\
$\mathrm{C}_{13}$ & $\mathrm{C}_{13}-\mathrm{O}_{14}$ & 1.415 & 0.232 & -0.041 & 0.049 \\
$\mathrm{O}_{14}$ & $\mathrm{O}_{14}-\mathrm{C}_{15}$ & 1.415 & $\mathbf{- 0 . 6 0 5}$ & 0.009 & 0.023 \\
$\mathrm{C}_{15}$ & $\mathrm{C}_{15}-\mathrm{C}_{16}$ & 1.436 & 0.031 & -0.019 & -0.013 \\
$\mathrm{C}_{16}$ & $\mathrm{C}_{16}-\mathrm{C}_{17}$ & $\mathbf{1 . 5 3 9}$ & 0.022 & -0.014 & $\mathbf{- 0 . 0 3 1}$ \\
$\mathrm{C}_{17}$ & $\mathrm{C}_{16}-\mathrm{N}_{18}$ & $\mathbf{1 . 5 2 8}$ & -0.334 & -0.006 & -0.011 \\
$\mathrm{~N}_{18}$ & $\mathrm{~N}_{18}-\mathrm{C}_{12}$ & 1.466 & -0.359 & 0.001 & $\mathbf{- 0 . 1 2 8}$ \\
$\mathrm{C}_{19}$ & $\mathrm{~N}_{18}-\mathrm{C}_{19}$ & 1.442 & -0.016 & 0.016 & 0.013 \\
$\mathrm{C}_{20}$ & $\mathrm{C}_{19}=\mathrm{C}_{20}$ & 1.345 & 0.025 & 0.011 & 0.020 \\
$\mathrm{C}_{21}$ & $\mathrm{C}_{20}-\mathrm{C}_{21}$ & 1.482 & 0.292 & 0.018 & 0.047 \\
$\mathrm{C}_{22}$ & $\mathrm{C}_{21}-\mathrm{C}_{11}$ & 1.477 & 0.533 & 0.018 & 0.036 \\
$\mathrm{O}_{23}$ & $\mathrm{C}_{20}-\mathrm{C}_{22}$ & 1.481 & $\mathbf{- 0 . 6 7 1}$ & 0.013 & 0.018 \\
$\mathrm{O}_{24}$ & $\mathrm{C}_{22}-\mathrm{O}_{23}$ & 1.393 & $\mathbf{- 0 . 3 7 9}$ & $\mathbf{0 . 0 3 1}$ & 0.063 \\
$\mathrm{O}_{25}$ & $\mathrm{C}_{22}=\mathrm{O}_{24}$ & 1.217 & $\mathbf{- 0 . 3 9 6}$ & $\mathbf{0 . 7 8 2}$ & 0.081 \\
$\mathrm{~F}_{26}$ & $\mathrm{C}_{21}=\mathrm{O}_{25}$ & 1.219 & -0.649 & 0.022 & 0.035 \\
\hline & & & & &
\end{tabular}

Mechanism of Inhibition

Corrosion inhibition mechanism in acidic medium is based on the adsorption of inhibitor on the metal surface. The process of adsorption is influenced by the nature and charge of the metal, 
the chemical structure of the inhibitor and the type of aggressive electrolyte. The inhibitor molecules are adsorbed over the metal surface by blocking the active sites in which direct acid attack, thereby protecting the metal from corrosion ${ }^{23}$. The structure of the studied compound has an oxygen heteroatom and $\mathrm{C}=\mathrm{O}$ bond, therefore inhibition of the corrosion of carbon steel of the studied molecule may be attributed to the adsorption of the studied molecule through the $\mathrm{C}=\mathrm{O}$ center, which is regarded as the center of adsorption onto the metal surface. The adsorption creates a barrier to mass and charge transfer and thus isolates metal from further attack of the corrosive anions ${ }^{19}$. The inhibitors may then combine with freshly generated $\mathrm{Fe}^{2+}$ ions on the metal surface forming an iron-inhibitor complex as shown in equation 13 and Figure 5.

$$
\begin{aligned}
& \mathrm{Fe} \rightarrow \mathrm{Fe}^{2+}+2 e^{-} \\
& \mathrm{Fe}+\text { inhibitor }{ }_{a d s} \rightarrow[\mathrm{Fe}-\text { inhibitor }]_{a d s}^{2+}
\end{aligned}
$$

Figure 5 shows a nucleophilic attack on the partially positive carbon atom and the intermediate of full negative charge onoxygen atom. The oxygen then becomes protonated to yield an iron-inhibitor complex. The protonated oxygen atoms are the atoms that facilitate adsorption onto the metal surface. From the resulting complex, it may be suggested that the studied compound inhibits carbon steel corrosion in acidic medium. The adsorption of the inhibitor on the metal surface therefore reduces the surface area available for corrosion ${ }^{9}$.

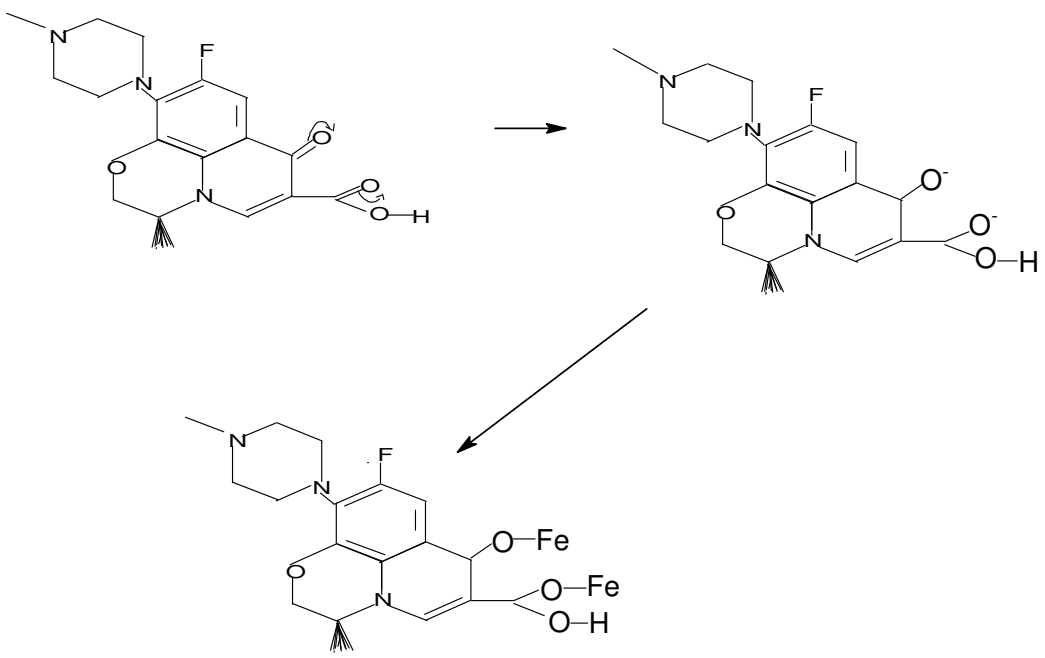

Figure 5. Inhibition mechanism of carbon steel corrosion in $2 \mathrm{M} \mathrm{HCl}$ for benzoxazin derivative

\section{Conclusion}

Quantum chemical study is adequately sufficient to predict the structure and molecule suitability of an inhibitor. Quantum chemical calculations reveal that the prefer site forelectrophilic and nucleophilic attack resides at the bonds $\mathrm{C}_{22}=\mathrm{O}_{24}, \mathrm{C}_{5}-\mathrm{N}_{2}, \mathrm{C}_{22}-\mathrm{O}_{23}$ and $\mathrm{C}_{11}-\mathrm{C}_{12}$ and at $\mathrm{N}_{18}-\mathrm{C}_{12}, \mathrm{C}_{16}-\mathrm{C}_{17}, \mathrm{C}_{4}-\mathrm{N}_{7}$ and $\mathrm{C}_{6}-\mathrm{C}_{5}$ respectively. In addition, based on the relatively high charge on atoms $\mathrm{O}_{23}, \mathrm{O}_{14}, \mathrm{O}_{25}$, and $\mathrm{O}_{24}$, electrophilic attack is expected to occur at $\mathrm{C}_{20}-\mathrm{C}_{22}, \mathrm{O}_{14}-\mathrm{C}_{15}, \mathrm{C}_{22}=\mathrm{O}_{24}$ and $\mathrm{C}_{22}-\mathrm{O}_{23}$. Benzoxazin derivative is a good corrosion inhibitor for carbon steel in acidic environment. The inhibitor possesses heteroatoms and functional groups that facilitate easy adsorption on the surface of steel. 


\section{Acknowlegdement}

The authors are grateful to the Corrosion and Electrochemistry Research Laboratory (CERLab.), Dept. of Pure and Applied Chemistry, UNICAL for research support.

\section{References}

1. Eddy N O, Odoemelam S A, Ogoko E C and Ita B I, Port Electrochim Acta, 2010, 28(1), 15-26; DOI:10.4152/pea.201001015

2. Okafor P C, Ebenso E E and Ekpe U J, Int J Electrochem Sci., 2010, 5, 978-993.

3. Ikpi M E, Abeng F E and Obono O E, World News Nat Sci., 2017, 9, 52-61.

4. $\quad$ Akpan I A and Offiong N O, Int J Chem Mater Res., 2014, 2(3), 23-29.

5. AkpanI A and Offiong N O, Chem Process Eng Res., 2014, 26, 20-23.

6. Attia E M, J Basic Appl Chem., 2015, 5(1), 1-15.

7. Abdel-Hameed R S, Ismail E A, Abu-Nawwas A H and Al-Shafey H I, Int J Electrochem Sci., 2015, 10, 2098-2109.

8. Karthikeyan S, Jeeva P A and Raja K, Int J ChemTech Res., 2015, 8(3), 1391-1395.

9. Abdullatef O A, J Adv Chem., 2015, 11(5), 3642- 3655.

10. Siaka A A, Eddy N O, Idris S O, Magaji L, Garba Z N and Shabanda I S, Int J Modern Chem., 2013, 4(1), 1-10.

11. Naqvi I, Saleemi A R and Naveed S, Int J Electrochem Sci., 2011, 6, 146-161.

12. Eddy N O, Stoyanov S R and Ebenso E E, Int J Electrochem Sci., 2010, 5, 1127-1150.

13. Ameh P O, Eddy N O and Koha P U, Chem Sci J., 2015, 6(3), 100; DOI: $10.4172 / 2150-3494.1000100$

14. Ikpi M E and Abeng F E, Int J Sci Res., 2017, 6(7), 623-628.

15. Mohammed M E and Taha K K, Researcher, 2012, 4(11), 92-97.

16. Obot I B, In: Developments in corrosion protection, In Tech; DOI:10.5772/57245

17. Young D C, Computational Chemistry: A practical Guide for Applying Techniques to Real-World Problems; John Wiley and Son Inc.: New York, 2001.

18. Jensen F, Introduction to Computer Chemistry; John Wiley and Sons Inc.: New York, 1999.

19. Fouda A S, Bekheit G E and El-Sherbari M W, J Bio Tribo-Corros., 2016, 2, 11; DOI:10.1007/s40735-016-0039-y

20. Shahabi S, Norouzi P and Ganjali M R, Int J Electrochem Sci., 2015, 10, 2646-2662.

21. Kabanda M M, Murulana L C, Ozcan M, Karadag F, Dehri I, Obot I B and Ebenso E E, Int J Electrochem Sci., 2012, 7, 5035-5056.

22. Elmsellem H, Nacer H, Halaimia F, Aouniti A, Lakehal I, Chetouani A, Deyab S S, Warad I, Touzani R and Hammonti B, Int J Electrochem Sci., 2014, 9, 5328-5351.

23. Karthikeyan S and Kumar S H, J Mater Environ Sci., 2012, 3(5), 925-934. 